\section{Should Digoxin Continue To Be Used for the Management of Atrial Fibrillation?}

\section{THE "PRO" SIDE}

Cardiac glycosides — including digoxin — have been used for centuries to treat patients with heart disease, including those with atrial fibrillation. ${ }^{1}$ However, the role of digoxin in the management of atrial fibrillation has recently been challenged, and its prominence in consensus guidelines minimized. ${ }^{2}$ Yet, digoxin does have a role and remains one of the treatment options, as an adjunct to a ß-blocker or calcium-channel blocker, to control heart rate, especially in patients with atrial fibrillation and heart failure with reduced ejection fraction (HFrEF). ${ }^{2}$ The purpose of this article is to reaffirm digoxin's position as a treatment option for patients with atrial fibrillation.

\section{Efficacy in Controlling Ventricular Response}

Digoxin lowers the heart rate by enhancing vagal tone, which leads to slowing of sinoatrial and atrioventricular nodal conduction and thereby a reduction in heart rate. ${ }^{1}$ Additionally, digoxin increases baroreceptor sensitivity, leading to sympatholytic activity, which may also contribute to the heart rate-slowing effects observed. ${ }^{1}$

An appropriately individualized dose of digoxin can yield effective heart rate control while minimizing adverse effects in patients with atrial fibrillation. To rapidly lower heart rate in these patients, a weight-based loading dose (about $10 \mu \mathrm{g} / \mathrm{kg}$ ) of digoxin should be given. ${ }^{1}$ Digoxin has a large volume of distribution, but distribution to the site of action (i.e., the heart) is prolonged, delaying the onset of activity and the peak effect on heart rate. ${ }^{1}$ Thus, the loading dose should be given in divided doses every 6-8 h. ${ }^{1}$ Renal clearance accounts for the majority of digoxin's elimination, although it is also a substrate for P-glycoprotein, which accounts for some nonrenal clearance. ${ }^{1}$ For patients whose renal function is preserved, the half-life of digoxin is about $36 \mathrm{~h}$, but the half-life can be longer than 4 days in patients with severe renal impairment. ${ }^{1}$ Although numerous dosing methods exist, all require adjustments based on weight (specifically, ideal body weight) and renal function, and the potential for drug-drug interactions (e.g., concomitant therapy with P-glycoprotein inhibitors) must also be accounted for in determining the dose of digoxin. ${ }^{1}$ Typical maintenance doses of digoxin in patients with atrial fibrillation range from 0.0625 to $0.25 \mathrm{mg}$ daily. ${ }^{1}$ Failure to account for one or more of the factors that influence digoxin dose increases the likelihood of adverse effects and may explain, in part, the observed associations between digoxin use and mortality risk.

Digoxin is most useful for heart rate control in patients with atrial fibrillation and HFrEF, where it is typically given as an adjunct to concomitant $B$-blocker therapy. ${ }^{2,3}$ In patients with atrial fibrillation and HFrEF, digoxin is advantageous because, unlike other agents (e.g., ß-blockers, calcium-channel blockers), it does not have negative inotropic effects, nor does it lower blood pressure. ${ }^{2}$ Additionally, because digoxin enhances vagal tone, it may have utility in controlling ventricular response in patients with sedentary lifestyles. As monotherapy, digoxin effectively improves control but not variability of heart rate, in part because it is less effective in controlling exercise-induced increases in heart rate. ${ }^{3,4}$ The clinician can overcome heart rate variability and achieve more effective control by combining digoxin with another heart rate control agent. ${ }^{2-4}$

\section{Digoxin Failing Clinicians/Patients, or Clinicians Failing Digoxin/Patients?}

Poor understanding of digoxin's limitations can lead to inappropriate use of this agent in patients with atrial fibrillation and may explain, in part, recent reports of associations between digoxin use and increased mortality. ${ }^{5,6}$ In the acute care setting, the peak effect of digoxin is delayed by several hours (about 3-6 h) because of the prolonged distribution phase and the required loading dose regimen (3 divided doses over $12-16 \mathrm{~h}$ ). ${ }^{1,2}$ Given the availability of more rapid-acting therapies (ß-blockers and calcium-channel blockers by IV administration), digoxin is not optimal as monotherapy to rapidly reduce heart rate but can be an effective adjunct to other therapies. ${ }^{2}$

Digoxin is relatively ineffective at controlling heart rate in highly sympathetic states, such as exercise. ${ }^{3,4}$ In patients with atrial fibrillation who exercise frequently or who have high sympathetic tone (e.g., those with hyperthyroidism, critical illness), digoxin monotherapy is not expected to be very effective as a heart rate control agent, a limitation that can be overcome through combination therapy. ${ }^{2-4}$

Another limitation-one that is often overlooked by clinicians - is the relatively flat dose-effect relation for heart rate control in atrial fibrillation. ${ }^{3,4}$ In one study, no significant differences in resting heart rate were observed between low-dose digoxin (0.25 mg daily, mean serum digoxin concentration $0.81 \mathrm{ng} / \mathrm{mL}$ 
[conversion to SI units: $1 \mathrm{ng} / \mathrm{mL}=1.281 \mathrm{nmol} / \mathrm{L}$ ]) and high-dose digoxin $(0.5 \mathrm{mg}$ daily, mean serum digoxin concentration $1.71 \mathrm{ng} / \mathrm{mL}) .{ }^{4}$ Despite evidence to the contrary, clinicians often inappropriately target higher serum digoxin concentration, incorrectly believing it will lead to better heart rate control, when in fact this strategy may increase the risk of adverse events, including death.

\section{Digoxin, Mortality Risk, and Serum Digoxin Concentration}

Over the past decade, numerous studies have suggested that digoxin use in patients with atrial fibrillation increases mortality risk. ${ }^{5,6} \mathrm{~A}$ meta-analysis of 11 observational studies found that the use of digoxin in patients with atrial fibrillation was associated with a $17 \%$ higher risk of death than among those not treated with digoxin. ${ }^{5}$ However, 2 additional meta-analyses yielded conflicting results regarding the association between digoxin and mortality risk. ${ }^{6,7}$ Thus, associations between digoxin use and increased mortality are, at best, inconclusive.

Many of the digoxin-mortality analyses failed to account for the influence of serum digoxin concentration on mortality. ${ }^{5-7}$ In patients with $\mathrm{HFrEF}$ treated with digoxin, serum digoxin concentration below $1.0 \mathrm{ng} / \mathrm{mL}$ has been associated with reduced mortality relative to placebo, whereas an increased mortality risk has been observed at serum digoxin concentration of $1.0 \mathrm{ng} / \mathrm{mL}$ or above. ${ }^{8}$ Most studies evaluating the use of digoxin in patients with atrial fibrillation generally achieved serum digoxin concentration of about $1.2 \mathrm{ng} / \mathrm{mL}$, above the threshold associated with increased mortality in patients with HFrEF. Indeed, the only digoxin-mortality study that reported serum digoxin concentration found that patients who died had higher levels than survivors $(1.2 \mathrm{ng} / \mathrm{mL}$ versus $0.9 \mathrm{ng} / \mathrm{mL}, p<0.001){ }^{9}$ Another study found that patients with atrial fibrillation treated with the combination of digoxin and dronedarone had higher cardiovascular mortality than those treated with digoxin alone; serum digoxin concentrations were significantly higher in the combination group $(1.1 \mathrm{ng} / \mathrm{mL}$ versus $0.7 \mathrm{ng} / \mathrm{mL}, p<0.0001) .{ }^{10}$ If an association between digoxin use and mortality risk exists, serum digoxin concentration is likely an important risk factor.

\section{Conclusion}

In appropriate patients (e.g., those with atrial fibrillation with HFrEF) and at low doses (targeting serum digoxin concentration $<1.0 \mathrm{ng} / \mathrm{mL}$ ), digoxin is an effective heart rate control agent, when given as an adjunct to other control therapies. However, improper patient selection and the use of unnecessarily high doses may lead to poor efficacy and increased risk of adverse events.

\section{References}

1. DiDomenico RJ, Page RL 2nd. Chapter 13: Digoxin. In: Murphy J, editor. Clinical pharmacokinetics. 6th ed. Bethesda (MD): American Society of Health-System Pharmacists; 2017. p. 239-50.
2. January CT, Wann LS, Alpert JS, Calkins H, Cigarroa JE, Cleveland JC Jr, et al. $2014 \mathrm{AHA} / \mathrm{ACC} / \mathrm{HRS}$ guideline for the management of patients with atrial fibrillation: a report of the American College of Cardiology/American Heart Association Task Force on Practice Guidelines and the Heart Rhythm Society. J Am Coll Cardiol. 2014;64(21):e1-76.

3. Nikolaidou T, Channer KS. Chronic atrial fibrillation: a systematic review of medical heart rate control management. Postgrad Med J. 2009;85 (1004):303-12.

4. Lang R, Klein HO, Weiss E, David D, Sareli P, Levy A, et al. Superiority of oral verapamil therapy to digoxin in treatment of chronic atrial fibrillation. Chest. 1983;83(3):491-9.

5. Ouyang AJ, Lv YN, Zhong HL, Wen JH, Wei XH, Peng HW, et al. Metaanalysis of digoxin use and risk of mortality in patients with atrial fibrillation. Am J Cardiol. 2015;115(7):901-6.

6. Vamos M, Erath JW, Hohnloser SH. Digoxin-associated mortality: a systematic review and meta-analysis of the literature. Eur Heart J. 2015; 36(28):1831-8.

7. Ziff OJ, Lane DA, Samra M, Griffith M, Kirchhof P, Lip GYH, et al. Safety and efficacy of digoxin: systematic review and meta-analysis of observational and controlled trial data. BMJ. 2015;351:h4451.

8. Ahmed A, Rich MW, Love TE, Lloyd-Jones DM, Alban IB, Colucci WS, et al. Digoxin and reduction in mortality and hospitalization in heart failure: a comprehensive post hoc analysis of the DIG trial. Eur Heart J. 2006; 27(2):178-86

9. Freeman JV, Reynolds K, Fang M, Udaltsova N, Steimle A, Pomernacki $\mathrm{NK}$, et al. Digoxin and risk of death in adults with atrial fibrillation: the ATRIA-CVRN study. Circ Arrhythm Electrophysiol. 2015;8(1):49-58.

10. Hohnloser SH, Halperin JL, Camm AJ, Gao P, Radzik D, Connolly SJ; PALLAS Investigators. Interaction between digoxin and dronedarone in the PALLAS trial. Circ Arrhythm Electrophysiol. 2014;7(6):1019-25.

Robert J DiDomenico, PharmD

Department of Pharmacy Practice

University of Illinois at Chicago

Chicago, Illinois

Competing interests: Robert DiDomenico received an Investigator Development Award from the American College of Clinical Pharmacy in 2008 and research funding from Glaxo Wellcome in 1999, for digoxin-related studies. He has served as an advisory board member for Amgen and Otsuka American Pharmaceutical, Inc, and received an honorarium from Amgen for preparation of a drug monograph.

\section{THE "CON" SIDE}

Digoxin has long been used for the management of various conditions, including atrial fibrillation, but we would argue that it should join the ranks of drugs such as reserpine, guanethidine, and bretylium, which are no longer used because of a relative lack of efficacy and concerns about safety.

Although digoxin has been used for hundreds of years, clinicians' understanding of its effects, in particular its mechanism of action, has evolved over time. It was once thought that digoxin was effective for converting atrial fibrillation to sinus rhythm, maintaining sinus rhythm, and preventing vagally mediated paroxysmal atrial fibrillation. However, it has been shown that digoxin is not effective in any of these situations. ${ }^{1}$ Small observational trials and randomized 
controlled trials with short follow-up periods (days to weeks) have demonstrated that digoxin decreases resting ventricular rate, ${ }^{2}$ yet rate control is not the only goal of therapy for a patient with atrial fibrillation. In today's management of atrial fibrillation, symptom control and quality of life are important goals, and the impact of digoxin on these end points is not well studied. Other problems that limit digoxin's usefulness are its slow onset of action in the acute scenario and its ineffectiveness in physically active individuals and those with high sympathetic tone.

The 2014 atrial fibrillation guideline of the American College of Cardiology, American Heart Association, and Heart Rhythm Society and the 2016 guideline of the Canadian Cardiovascular Society do not recommend digoxin as a first-line rate control agent. ${ }^{3,4}$ They acknowledge that although digoxin is commonly used, there are only select patients in whom it will be effective. In addition to lack of efficacy, the guidelines raise concern that digoxin may increase mortality, as seen in various retrospective analyses of randomized controlled trials and cohort studies. One example is the ATRIACVRN study, a retrospective cohort study that included 14787 adult patients from the Kaiser Permanente California database who had a diagnosis of atrial fibrillation but no heart failure with reduced ejection fraction (HFrEF). ${ }^{5}$ The patients were matched for age, sex, and a high-dimensional propensity score. Incident digoxin use was independently associated with increased mortality ( 8.3 versus 4.9 per 100 person-years, $p<0.001)$. A similar finding was shown in registry data for 9619 patients with atrial fibrillation collected from 174 sites in the United States. ${ }^{6}$ That study found that incident digoxin use was associated with subsequent death among patients who had atrial fibrillation but not HFrEF (propensity-adjusted hazard ratio [HR] $1.99,95 \%$ confidence interval [CI] 1.12-3.56).

A meta-analysis by Qureshi and others ${ }^{7}$ included data from retrospective analyses and observational trials published between 1997 and 2013. Using a random-effects model, the authors found a $27 \%$ increase in risk of mortality for individuals who used digoxin relative to those who did not (pooled HR 1.27, 95\% CI 1.19-1.36, $p<0.001){ }^{7}$ This association between digoxin and increased all-cause mortality appeared to be more prominent for patients who had atrial fibrillation without HFrEF (pooled HR 1.47, 95\% CI 1.25-1.73, $p<0.001)$ than for patients having both atrial fibrillation and HFrEF (pooled HR 1.21, 95\% CI 1.07-1.35, $p=0.002$ ). Another meta-analysis that included contemporary data (2008-2015) also demonstrated that digoxin use was associated with a higher risk of mortality for all patients with atrial fibrillation (HR 1.23, 95\% CI $1.16-1.31, p<0.00001$ ), but when the data were stratified, the higher risk was limited to patients who had atrial fibrillation without HFrEF (HR 1.38, 95\% CI 1.12-1.71, $p=0.003$ ); it did not occur among those with both atrial fibrillation and HFrEF (HR 1.08, 95\% CI $0.99-1.18, p=0.09)$. $^{8}$

In one meta-analysis that examined the efficacy and safety of digoxin in patients with HFrEF and/or atrial fibrillation, there was no increase in mortality associated with digoxin use. ${ }^{9}$ However, this conclusion was based upon an analysis that was limited to randomized controlled trials (risk ratio [RR] 0.99, 95\% CI 0.93-1.05), and these trials did not include patients with atrial fibrillation who did not have heart failure. In other analyses that did include such patients, there was an increased risk of mortality in the digoxin group (for example, RR 1.18, 95\% CI 1.09-1.26, in propensity matched studies). The authors did not draw any conclusions regarding the effect of digoxin on mortality in patients with atrial fibrillation who do not have HFrEF.

There seems to be a strong signal that digoxin may be harmful when used for rate control in patients with atrial fibrillation without HFrEF. It should be noted that this information comes from retrospective analyses and observational data, not randomized controlled trials. Consequently, it is important to recognize that some but not all confounders may be accounted for in either the propensity matching or risk adjustments that were used in the analyses. In addition, there is inherent bias, as it is not known why digoxin was prescribed for these individuals. Despite these limitations, clinicians should be concerned about using digoxin in this population. Although one might think that only a small number of patients will receive digoxin, given that the guidelines relegate this agent to second-line or add-on therapy, it is used commonly. For example, in some recent trials of stroke prevention involving patients with atrial fibrillation, rates of digoxin use ranged from $29 \%$ to $39 \%$. $^{10,11}$

Another meta-analysis on this topic is being planned, ${ }^{12}$ but the results will be subject to the limitations of the existing publications. A randomized controlled trial on the effect of digoxin on all-cause mortality in patients who have atrial fibrillation with or without HFrEF (most urgently the latter) would provide better information. The RATE-AF trial, a comparison of bisoprolol and digoxin as rate control agents, is currently recruiting participants, and results are expected in 2019.13 Although this trial will provide some information on a variety of efficacy-related end points (e.g., SF-36 measured quality of life, 6-min walk test, heart rate), it is unlikely to provide information on mortality because of its small sample size (160 participants). Furthermore, an adequately sized trial is unlikely to be performed, for several reasons: the challenge of participant recruitment when there is a potential for harm, the large sample size required when mortality is an end point, and the need to secure funding for such a trial. Given this reality, clinicians need to act on the information available. With a lack of efficacy data and concerns about safety, particularly among patients without HFrEF, we assert that digoxin should be added to the list of "DO NOT USE" drugs.

\section{References}

1. Falk RH, Leavitt JI. Digoxin for atrial fibrillation: a drug whose time has gone? Ann Intern Med. 1991;114(7):573-5.

2. Redfors A. The effect of different digoxin doses on subjective symptoms and physical working capacity in patients with atrial fibrillation. Acta Med Scand. 1971;190(4):307-20.

3. January CT, Wann LS, Alpert JS, Calkins H, Cigarroa JE, Cleveland JC Jr, et al. $2014 \mathrm{AHA} / \mathrm{ACC} / \mathrm{HRS}$ guideline for the management of patients with atrial fibrillation; a report of the American College of Cardiology/American Heart Association Task Force on Practice Guidelines and the Heart Rhythm Society. J Am Coll Cardiol. 2014;64(21):e1-76. 
4. Macle L, Cairns J, Leblanc K, Tsang T, Skanes A, Cox JL, et al.; CCS Atrial Fibrillation Guidelines Committee. 2016 focused update of the Canadian Cardiovascular Society guidelines for the management of atrial fibrillation. Can J Cardiol. 2016;32(10):1170-85.

5. Freeman JV, Reynolds K, Fang M, Udaltsova N, Steimle A, Pomernacki $\mathrm{NK}$, et al. Digoxin and risk of death in adults with atrial fibrillation: the ATRIA-CVRN study. Circ Arrhythm Electrophysiol. 2015;8(1):49-58.

6. Allen LA, Fonarow GC, Simon DN, Thomas LE, Marzec LN, Pokorney $\mathrm{SD}$, et al.; ORBIT-AF Investigators. Digoxin use and subsequent outcomes among patients in a contemporary atrial fibrillation cohort. J Am Coll Cardiol. 2015;65(25):2691-8.

7. Qureshi W, O’Neal WT, Soliman EZ, Al-Mallah MH. Systematic review and meta-analysis of mortality and digoxin use in atrial fibrillation. Cardiol J. 2016;23(3):333-43.

8. Chamaria S, Desai AM, Reddy PC, Olshansky B, Dominic P. Digoxin use to control ventricular rate in patients with atrial fibrillation and heart failure is not associated with increased mortality. Cardiol Res Pract. 2015;2015: 314041.

9. Ziff OJ, Lane DA, Samra M, Griffith M, Kirchhof P, Lip GYH, et al. Safety and efficacy of digoxin: systematic review and meta-analysis of observational and controlled trial data. BMJ. 2015;351:h4451.

10. Patel MR, Mahaffey KW, Garg J, Pan G, Singer DE, Hacke W, et al.; ROCKET AF Investigators. Rivaroxaban versus warfarin in nonvalvular atrial fibrillation. N Engl J Med. 2011;365(10):883-91.
11. Granger CB, Alexander JH, McMurray JJV, Lopes RD, Hylek EM, Hanna $\mathrm{M}$, et al.; ARISTOTLE Committees and Investigators. Apixaban versus warfarin in patients with atrial fibrillation. $N$ Engl J Med. 2011; 365(11): 981-92.

12. Sethi NJ, Safi S, Feinberg J, Nielsen EE, Gluud C, Jakobsen JC. Digoxin versus placebo, no intervention, or other medical interventions for atrial fibrillation and atrial flutter: a protocol for a systematic review with metaanalysis and trial sequential analysis. Syst Rev. 2017;6(1):71.

13. University of Birmingham. Rate control therapy evaluation in permanent atrial fibrillation (RATE-AF) [trial registration]. Bethesda (MD): National Institutes of Health; 2015 Feb 27 [updated 2017 May 5; cited 2017 Jun 14]. Available from: www.clinicaltrials.gov/ct2/show/NCT02391337?term= digoxin\&cond=\%22Arrhythmias $\% 2 \mathrm{C}+\mathrm{Cardiac} \% 22 \&$ rank $=5$

Ann Leung, ACPR, PharmD

Heather Kertland, PharmD, FCSHP

Pharmacy

St Michael's Hospital

Toronto, Ontario

Competing interests: None declared.

\section{ON THE FRONT COVER}

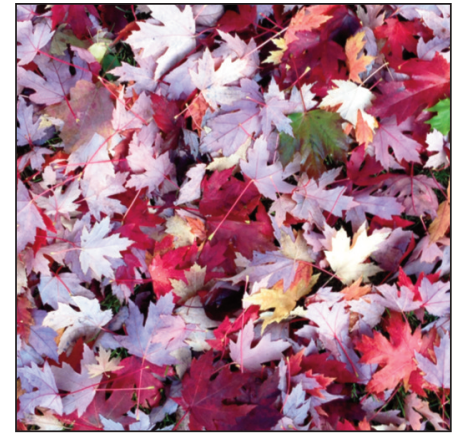

\section{Autumn leaves London, Ontario}

This issue's cover photograph was taken by Linda Hooper, using an iPhone 5, during her walk home from the London Health Sciences Centre, where she is a Drug Information Pharmacist with LonDIS.
"Being from Northern Ontario, I have a deep appreciation for fall colours. When the weather permits, I enjoy the opportunity to walk. It allows me the chance to either prepare for the day ahead or reflect on the day that's just passed. The walk during which I took this photograph was very satisfying, even if the route was a bit longer than usual."

The CJHP would be pleased to consider photographs featuring Canadian scenery taken by CSHP members for use on the front cover of the Journal. If you would like to submit a photograph, please send an electronic copy (minimum resolution $300 \mathrm{dpi}$ ) to publications@cshp.ca. 